\title{
Heat Illness Prevention in the OUtdoor WORKPLACE
}

\author{
Tyler D. Asher M.S and Ian McAndrew \\ Capitol Technology University, Laurel, Maryland
}

\begin{abstract}
In the construction industry a large amount of work is completed outdoors where the sun may expose or heat up rooms that can affect employees while working. This research will recognize how companies combat with heat illness and heat prevention methods to keep employees healthy and safe while working in high temperatures. Each year in the United States thousands of employees fall ill to heat related illnesses, stem from heat rash to heat stroke, which can be fatal, if not treated properly. Research will examine what standards are required by the Occupational Safety \& Health Administration (OSHA) and how many participants companies currently abide by those standards. Every day that employees who work outdoors or in high temperature facilities go without proper training and education about heat stress, the number of cases will rise and more will become ill to heat related complications. This study will give prevention methods to help keep American workers safe.
\end{abstract}

\section{KEYWORDS}

Heat Stress; Heat Illness; Heat Rash; Heat Cramps; Heat Exhaustion; Heat Stroke; OSHA

\section{INTRODUCTION}

Heat illness is observed when the body overheats from stress due to high volumes of heat. There are four categories of heat illness: heat rash, heat cramps, heat exhaustion and heat stroke. Heat related illness is prevalent for employees who are at risk to high heat, humidity, and hot surfaces (Rogers, 2007). From 2004-2019, an average of 700 heat-related deaths (410 with heat as the underlying cause and 290 as a contributing cause) occurred in the United States annually (CDC, 2020). In the construction industry a large amount of work is completed outdoors where the sun may expose or heat up rooms that can affect employees while working. The focus of this study is heat awareness in the outdoor workplace, with an understanding of the different types of heat illness. The scope is to encourage workers to take preventive measures to combat heat stress. With continuous training, organizations can help reduce preventive deaths when dealing with heat stress. 
Health Informatics - An International Journal (HIIJ) Vol.10, No.2, May 2021

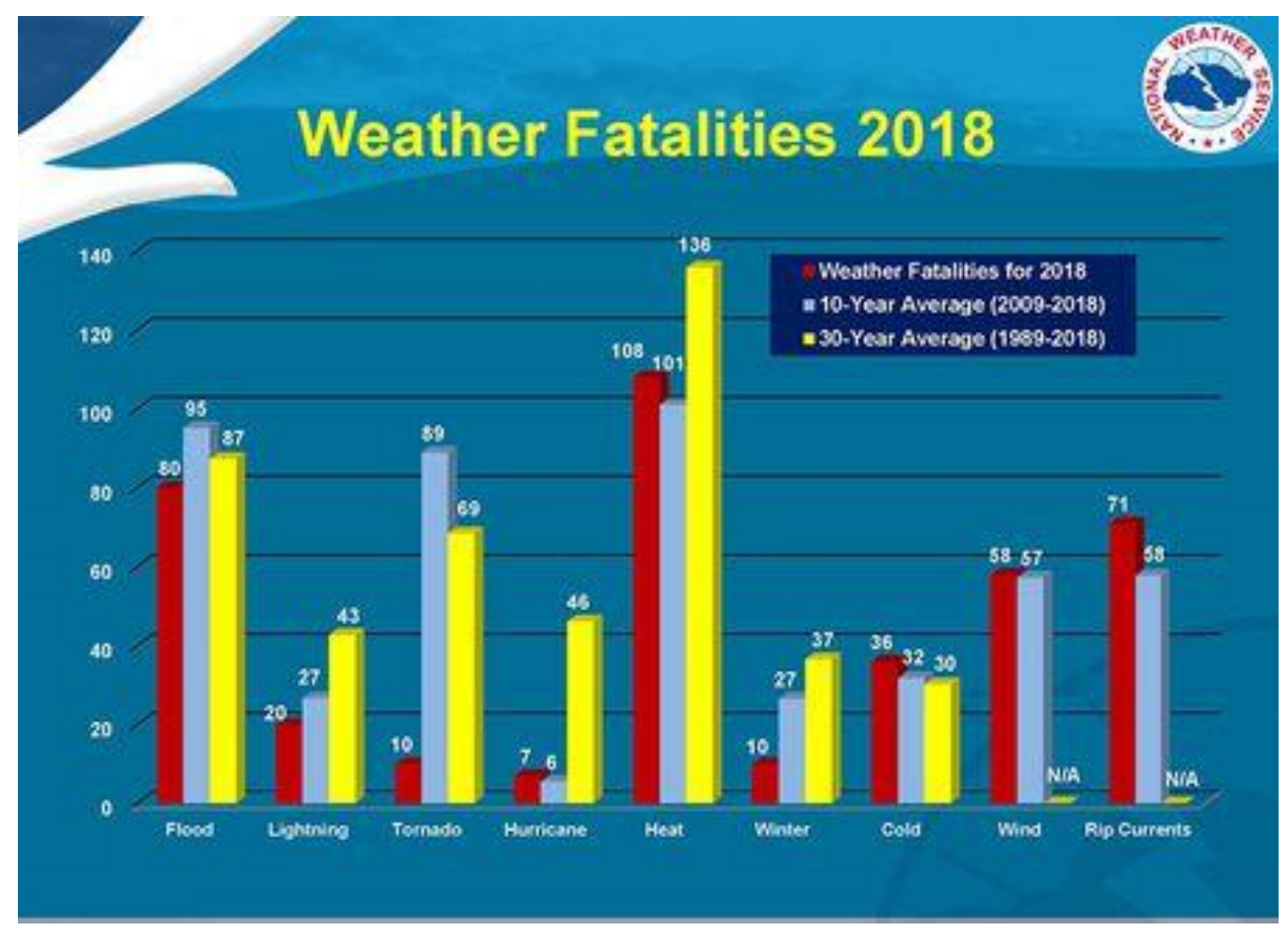

Figure 1: Weather mortality rates in 2018 (CDC, 2018)

\section{THEORY}

Heat related cramps is the most common ailment of heat stress. In all cases management and employees should look out for the signs and symptoms during the hotter months, these signs and symptoms consist of red itchy rash, muscle spasms, cool clammy skin, intense thirst, heavy sweating, fatigue, increased heart rate, dizziness, confusion, black outs, blurred vision, and death (CDC, 2017). Heat stress in times of extreme heat can be defined as summertime temperatures that can be much hotter than cooler seasons. During these times, an employee may experience heat exhaustion or heat stroke, this is when the body is not able to cool its self-down fast enough. When the body starts to experience extreme heat, the body then begins to sweat, but during extreme heat this may not be enough to cool the body down. In some cases, an employee's body temperature rises quicker than it can cool down. This may lead to organ shutdown or even organ failure (CDC, 2017). Employees most at risk are older adults, and people with mental illness and chronic diseases are at highest risk. However, even young, and healthy people can be affected if they participate in vigorous physical activities during hot weather (CDC, 2017)

Table 1: (CDC, 2017)

Some factors that might increase your risk of developing a heat-related illness include:

- High levels of humidity

- Heart disease

- Obesity

- Mental illness

- Fever

- Poor circulation

- Dehydration

- Sunburn

- Prescription drug use

- Alcohol use 


\section{HYPOTHESIS}

Null Hypothesis:

Higher levels of training will increase the awareness of heat stress. (One-tailed test)

Alternative Hypothesis:

Increased training will not improve awareness of employee getting heat stress.

\section{MeTHODS}

Target groups were selected based on employment status (employed, unemployed, and selfemployed). Selecting a quantitative design, we selected 25 targets on LinkedIn who worked for all kinds of different companies as health and safety professionals and gave them a survey based on their knowledge of heat stress awareness in the workplace. LinkedIn serves as a platform for professional networking and independent studies. Twenty-five people agreed to participate, of whom 16 were men and 9 were women; they had an average age of 43.5, all were tenured employees with 4 years of employment, and 24 were currently employed. The key results will show how many would want to see their employer train more frequently. The instrument used to pull data was Survey Monkey. Small samples were used with a 5-point Likert scale; this gave us a broader range of answers.

The second portion of the study estimated how many companies train their employees on heat illness prevention. Another survey using a 5-point Likert scale was sent out on LinkedIn. Surveys were started on January 18th, 2020 and ran for 14 days. Participants were asked to partake in a short survey on heat awareness in the workplace. No more guidance was given at that time unless participants had questions. Surveys took 1 minute and 06 seconds on average to complete. There were 7 questions total. No human research ethics were used to retrieve survey results.

\section{RESUltS}

1. Do you think your employer should train you on heat stress?

2. Does your employer perform adequate training on heat stress?

3. Should your employer offer water, shade, etc.

4. Would you be more willing to be trained on heat stress if your employer paid for it?

5. Do you know the signs and symptoms of heat stress?

6. Would it be important to know the amount of heat stress cases companywide?

7. Would knowing company profit lost due to heat illness interest you?

\begin{tabular}{|c|c|c|c|c|c|c|}
\hline Questions & Total Participants & Strongly Agree $\%$ & Agree $\%$ & Undecided \% & Disagree \% & Strongly Disagree \% \\
\hline Question 1 & 25 & $37.50 \%$ & $50 \%$ & $0.00 \%$ & $6.25 \%$ & $6.25 \%$ \\
\hline Question 2 & 25 & $12.50 \%$ & $37.50 \%$ & $12.50 \%$ & $18.75 \%$ & $18.75 \%$ \\
\hline Question 3 & 25 & $50.00 \%$ & $50.00 \%$ & $0.00 \%$ & $0.00 \%$ & $0.00 \%$ \\
\hline Question 4 & 25 & $37.50 \%$ & $50.00 \%$ & $0.00 \%$ & $12.50 \%$ & $0.00 \%$ \\
\hline Question 5 & 25 & $25.00 \%$ & $50.00 \%$ & $6.25 \%$ & $12.50 \%$ & $6.25 \%$ \\
\hline Question 6 & 25 & $37.50 \%$ & $37.50 \%$ & $12.50 \%$ & $6.25 \%$ & $6.25 \%$ \\
\hline Question 7 & 25 & $31.25 \%$ & $43.75 \%$ & $12.50 \%$ & $6.25 \%$ & $6.25 \%$ \\
\hline
\end{tabular}

Figure 2 
Health Informatics - An International Journal (HIIJ) Vol.10, No.2, May 2021

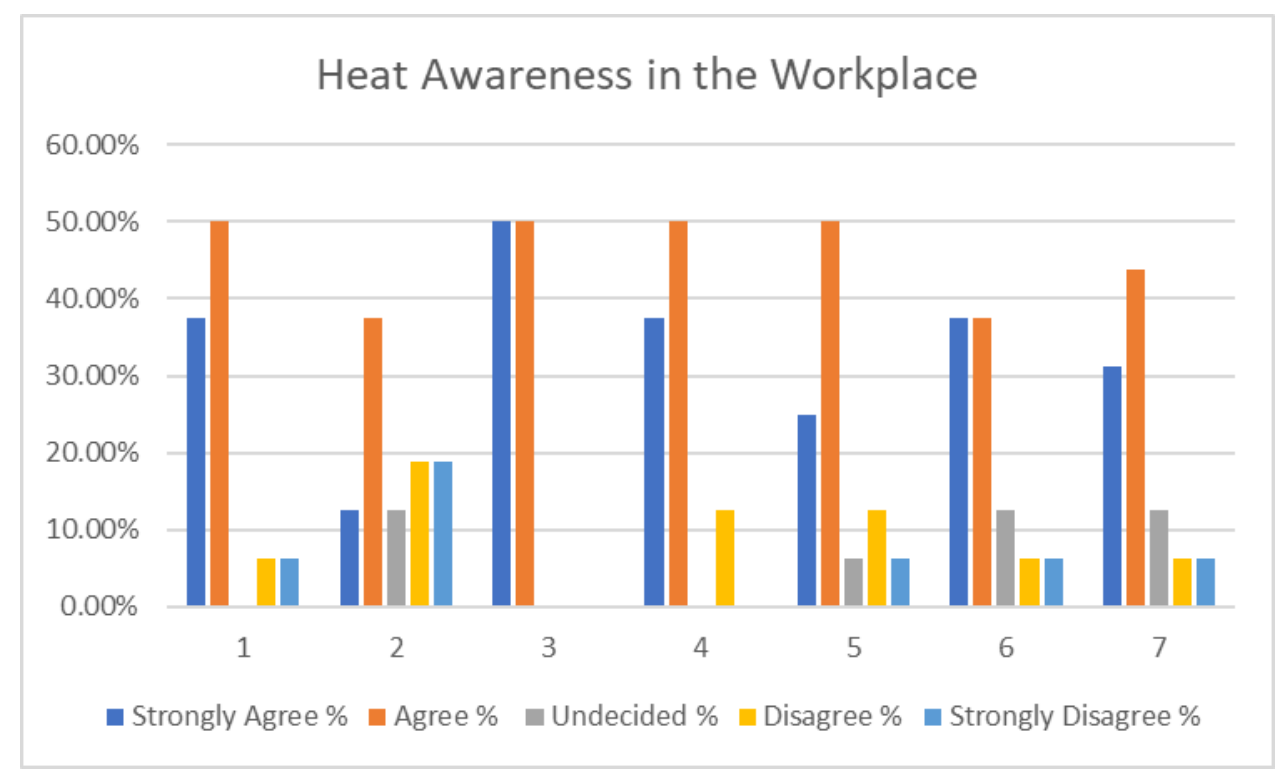

Figure 3

\section{CONClusion}

Based on the questions presented in the survey, we can conclude that heat stress awareness is high among employees, but training is needed to better educate employees. It was also found that several companies have developed policies and procedures but lack any type of heat illness program for their employees. More studies are needed to better understand what direct training is needed to follow heat stress awareness polices. ANOVA is 95\% confidence; we do not reject the null hypothesis and conclude that the average score it takes to process applications is $95 \%$ confident.

\section{REFERENCES}

[1] Tymvios, N., Behm, M., \& Jia, Y. A. (2019). HEAT ILLNESS. Professional Safety, 64(6), 40-45. Retrieved from https://franklin.captechu.edu:2074/docview/2238481119?accountid=44888

[2] Maher, Helen K, PhD, RN, COHN-S,C.C.M., F.A.A.O.H.N. (2007). Preventing heat-related illness. AAOHN Journal, 55(9), 388. $\quad$ Retrieved from https://franklin.captechu.edu:2074/docview/219391076? accountid=44888

[3] Rogers, Bonnie, DrPH, COHN-S,L.N.C.C., F.A.A.N., Stiehl, Kristin, RN,B.S.N., C.C.M., Borst, Jennifer, RN,B.S.N., C.O.H.N., Hess, Andrea, RN,B.S.N., C.E.N., \& Hutchins, Shauna, RN,B.S.N., B.A. (2007). Heat-related illnesses: The role of the occupational and environmental health nurse. AAOHN Journal, 55(7), 279-287. Retrieved from https://franklin.captechu.edu:2074/docview/219374723?accountid=44888

[4] Vaidyanathan A, Malilay J, Schramm P, Saha S. Heat-Related Deaths — United States, 2004-2018. MMWR Morb Mortal Wkly Rep 2020;69:729-734. DOI: http://dx.doi.org/10.15585/mmwr.mm6924a1external icon

[5] Ballester F, Dolores C, Perez-Hoyos S, Saez M, Hervas A. Mortality as a function of temperature. A study in Valencia, Spain, 1991-1993. International Journal of Epidemiology 1997; 26(3):551-61.

[6] Chestnut LG, Breffle WS, Smith JB, Kalkstein LS. Analysis of differences in hot-weather-related mortality across 44 U.S. metropolitan areas. Environmental Science \& Policy 1998; 1:59-70. 